\title{
Observations on mating in Mediterranean Sepiola and Sepietta species and review of mating behaviour in Sepiolinae (Cephalopoda: Sepiolidae)
}

\author{
Giambattista Bello ${ }^{1^{*}}$ (D) and Adrianne Deickert ${ }^{2}$
}

\begin{abstract}
Mating was observed and described in captive individuals of Sepiola affinis, Sepiola intermedia and Sepietta obscura (Cephalopoda: Sepiolidae) collected in the Catalan Sea, western Mediterranean Sea. This is the first report of a mating event in S. intermedia; it is also the first detailed description of the mating behaviour for the other two species. The published literature on mating in Sepiolinae, which includes both cursory reports and in-depth descriptions of mating events, was thoroughly reviewed. In all, copulation has been examined in eight species belonging to four different genera, namely, Eumandya, Euprymna, Sepietta and Sepiola, starting from 1894 to the present. Common traits of the mating behaviour were detected among the studied sepioline species, so that a general five stages succession of actions is established to portray the mating progress in Sepiolinae: (A) female hovers by, male attention (it is discussed whether actual copulation is preceded by any courtship); (B) male approaches female from below; (C) male grasps female at the neck by its third arms, inserts its first arms in the female's mantle cavity (the hectocotylised left arm is thus aligned with the bursa copulatrix), holds the female's mantle by its second arms and positions itself and mate in the "parallel position"; (D) copulation and transfer of spermatophores from male to female (this stage may last from 3 min to 3 h); (E) mating dissolution. Mating occurs preferentially during the dark hours; it is described as violent and the female tries to escape the forceful grasp by the male; the male skin coloration turns darker. The similarity of the mating behaviour in all examined sepioline species is an evidence of both its evolution in harmony with their copulatory organs (hectocotylus and bursa copulatrix) and, seemingly, its common derivation to the whole Sepiolinae clade.
\end{abstract}

Keywords: Cephalopoda, Sepiolinae, Behaviour, Mating, Reproduction, Mediterranean Sea

\section{Introduction}

Mating is an important event in the life of animals, because through its success, they perpetuate their populations and species. Coleoid cephalopods, all of them gonochoric, are known to reproduce using spermatophores transferred from the male to the female during copulation (e.g., Mangold-Wirz, 1963). In most

Editorial handling: Dirk Fuchs

*Correspondence: giamb.bello@gmail.com

${ }^{1}$ Mola di Bari, Italy

Full list of author information is available at the end of the article cephalopod species one arm, or more than one or a part of it, is modified into a hectocotylus or copulatory arm designed to transfer spermatophores during copulation (e.g., Naef, 1923), which is carried out according to genetically determined processes (see Hanlon and Messenger (2018) regarding mating behaviours).

Sepiolinae (Cephalopoda: Sepiolida: Sepiolidae), one of the three subfamilies into which the family Sepiolidae is currently subdivided, is characterized in having small sized species, the bursa copulatrix (copulatory pouch) in the female's left mantle cavity and the left dorsal arm hectocotylized in males (Bello, 2020). Sepiolinae is deemed 
a fairly homogeneous, i.e., monophyletic taxon (Bello, 2020). It contains some 36 well established species of which only seven have actually been observed during mating: Eumandya parva (Sasaki, 1914) (Drerup et al., 2020), Euprymna hyllebergi Nateewathana, 1997 (Nabhitabhata et al., 2005), Euprymna scolopes Berry, 1913 (Hanlon et al., 1997; Moynihan, 1983; Singley, 1983); Euprymna tasmanica (Pfeffer, 1884) (Squires et al., 2013), Sepietta obscura Naef, 1916 (Deickert, 2009), Sepiola affinis Naef, 1912 (Mangold-Wirz, 1963; Mauris, 1988), Sepiola atlantica d'Orbigny, 1842 (Goud et al., 2019; Jones \& Richardson, 2010; Levy, 1912; Racovitza, 1894; Rodrigues et al., 2009) and Sepiola sp. (Boletzky 1983). The mating behaviour of sepioline squids is satisfactorily described only in some of these papers.

Hanlon and Messenger (2018) concisely summarize in a table the available data (the most recent published paper is from 2012). They refer three different mating position reported for Sepiolinae in the pertinent literature: male-to-female-neck, male-parallel, head-to-head. According to this as well as other details (see the present "Discussion"), it is quite evident that there are discrepancies among reports of the mating behaviour in Sepiolinae, which invites a review of this subject. As for mating positions, figurative documents (drawings and photographs) report only two mating positions: male-to-female-neck (drawing in Mangold-Wirz, 1963, Fig. 4a) and male-parallel (all others), despite the fact that in the latter papers the actual male-parallel (or simply parallel) position is also erroneously named male-to-female-neck, which appears to be just a matter of nomenclatural confusion.

In the present paper we report the first accurate descriptions of mating in Sepiola intermedia Naef, 1912 and give additional information about the mating behaviour in Sepiola affinis and Sepietta obscura. All these three species are endemic or quasi-endemic to the Mediterranean Sea. Moreover, we review all previous descriptions of the mating behaviour in sepioline squids and provide an overall synthesis for the Sepiolinae subfamily.

\section{Materials and methods}

Sampling was carried out on sandy and muddy bottoms in the Catalan Sea off Banyuls-sur-Mer (Western Medi-

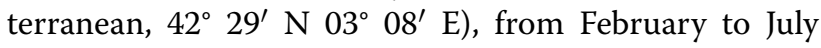
1988 and 1989, one to three times per week. A small beam trawl-mouth $0.8 \mathrm{~m}$ wide, net length $3 \mathrm{~m}$, mesh size $5 \mathrm{~mm}$, cod end with $0.7 \mathrm{~mm}$ mesh size-was used. Specimens of Sepiola affinis, Sepiola intermedia and Sepietta obscura were collected from 4 to $20 \mathrm{~m}$ depth. In addition, some sepiolines of the same species were hand caught during four night-dives of $1 \mathrm{~h}$ each, at the same depths and grounds as the trawl samples. In all, about 450 sepiolines were collected, $16 \%$ of which were sexually mature, belonging to Sepiola affinis, Sepiola intermedia, Sepiola robusta, Sepiola rondeletii and Sepietta obscura.

Soon after capture, the undamaged specimens were transferred to aquarium tanks in the laboratory. Submature and mature females were kept separated from each other in $5 \mathrm{~L}$ cylindrical glass containers (diameter $=20 \mathrm{~cm}$ ). Mature males and immature specimens were kept together in $50 \mathrm{~L}$ plastic tanks. The bottom of all containers was covered with a $1 \mathrm{~cm}$ thick layer of sand, collected from the same site, where the experimental specimens were caught. The containers were supplied with running sea water pumped from $10 \mathrm{~m}$ of depth and filtered through a gravel bed. Water temperatures ranged from $9{ }^{\circ} \mathrm{C}$ in February to $23^{\circ} \mathrm{C}$ in July, which was close to the temperature range in the field at about $10 \mathrm{~m}$ depth (Bhaud et al., 1967). To ensure normal lightdark periodicity, the experimental containers were situated in a room with natural daylight. The specimens were fed live mysids, and palaemonid and crangonid shrimps ad libitum.

The containers holding the sampled sepiolines were monitored during daily routine visits in the morning (8:30) and in the evening (17:30); additional observations were also carried out randomly at different hours. On several occasions, males were temporarily transferred into female containers (one male for each female) for mating and spawning stimulation.

Upon death, the experimental sepiolines were identified to species, following the descriptions by Naef (1923), and measured: dorsal mantle length (ML), head width (HW) and body mass (BM).

For the sake of clarity in describing mating events, we use the determiners 'his' and 'her' for male and female, respectively, although they are inappropriate terms for non-human animals.

\section{Results}

Mating was observed in four instances, two for Sepiola affinis, one for Sepiola intermedia and one for Sepietta obscura. The size of specimens involved in mating is reported in Table 1.

\section{Sepiola affinis}

Mating in both S. affinis cases, which involved two different pairs, occurred early at night. No substantial differences were detected between the observed mating events; hence the following description effectively portrays both of them.

No evident preliminary courtship behaviour was observed in either case. In fact, when transferred to a female's container, the male settled at the bottom of the tank. It was attracted by the female only when the latter hovered well above the ground (it is not clear whether 
Table 1 Sepioline pair data

\begin{tabular}{|c|c|c|c|c|c|c|c|c|}
\hline Species & Sex & $\begin{array}{l}\text { Mantle } \\
\text { length } \\
(\mathrm{mm})\end{array}$ & $\begin{array}{l}\text { Head } \\
\text { width } \\
(\mathrm{mm})\end{array}$ & Body mass (g) & Date of capture & Mating day & $\begin{array}{l}\text { 1st spawning day/ } \\
\text { number of laid eggs }\end{array}$ & Day of death \\
\hline \multirow[t]{2}{*}{ Sepiola affinis } & Female & 14.8 & 13.5 & 1.8 & 22.2 .88 & 65th & 80th/39 & 86th \\
\hline & Male & 18.5 & 17.4 & 3.8 & 1.4 .88 & 27 th & - & 30th \\
\hline \multirow[t]{2}{*}{ Sepiola affinis } & Female & 14.0 & 13.5 & 1.7 & 22.6 .88 & 16th & 17 th/44 & 26th \\
\hline & Male & 18.8 & 16.0 & 2.4 & 23.2 .88 & 135th & - & 137th \\
\hline \multirow[t]{2}{*}{ Sepiola intermedia } & Female & 17.2 & 14.7 & 2.8 & 16.2 .89 & $1 s t$ & No spawning & 5 th \\
\hline & Male & 19.2 & 18.3 & 4.1 & 16.2 .89 & $1 s t$ & - & 5th \\
\hline \multirow[t]{2}{*}{ Sepietta obscura } & Female & 16.8 & 17.3 & 3.7 & 4.5 .88 & 58th & 67 th/113 & $81 \mathrm{st}$ \\
\hline & Male & 23.3 & 15.0 & - & 5.5 .88 & 57 th & - & 68th \\
\hline
\end{tabular}

Measurements taken post-mortem

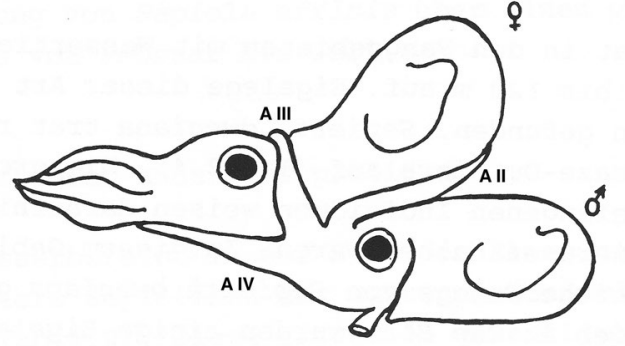

Fig. 1 Mating in Sepiola affinis, Sepiola intermedia and Sepietta obscura (drawing @ Adrianne Deickert)

the male saw the female just then), as shown by his eyes following the mate-to-be for a few seconds. Shortly after, the male displayed a sudden colour intensification and jumped aggressively onto the female from underneath with his arms stretched, grabbed her by his arms III placed between her head and mantle, and positioned himself under the female so that the latter's ventral side came to lay on his own head and neck dorsal side, i.e., in the parallel position (Fig. 1). For a few seconds, the female shook vigorously, seemingly in trying to get free. When positioning appeared completely set, the male's ventral arms were stretched out underneath the head of the female, its arms II held the sides of the female's mantle and lifted it; the female's mantle was thus bent upwards (Fig. 1). The male's arms of the first pair (which include the hectocotylus, i.e., left dorsal arm) were not visible because of their insertion in the female mantle cavity. Mating lasted between 30 and $45 \mathrm{~min}$, during which time the paired sepiolines either moved around slowly swimming in concert by their fin movements or sunk to the bottom of the container. The copulation appeared to be violent.

In one case, the next day, although there was much food available in the container only one small shrimp was eaten: mating was probably very exhausting for both mates. Both mated females laid egg batches within 15 days after mating (Table 1), a sign that it had been successful.

In two other cases, when a male was placed and kept in a female's container from early night to morning, seemingly no mating occurred. In fact, the post-mortem inspection of the two supposedly unmated females showed that their bursa copulatrix had no implanted spermatangia.

\section{Sepiola intermedia}

Mating was observed only once in S. intermedia. It took place in a bucket on the boat, where all collected sepiolines had been placed, right after sampling, at $11 \mathrm{am}$.

It lasted more than $60 \mathrm{~min}$. The parallel mating position and other observations closely matched the above description for the S. affinis copulations.

\section{Sepietta obscura}

One mating event was observed in this species following the transfer of a male to a single female's container. It occurred in the evening when there was still natural light.

The female appeared to be disturbed by the male's movement and started to swim. The male, when saw the female, jumped on her. The two mates were soon in parallel position, exactly like that above described for $S$. affinis and S. intermedia. Mating appeared to be very violent: the female struggled very hard and ejected brown ink. Mating lasted only $3 \mathrm{~min}$, during which time the mating pair swam continuously, never settling on the ground, until the male suddenly left the female. A few minutes later, the male settled on the ground and, later 
on, the female did the same and the two animals came to settle beside each other. The female appeared somewhat distressed; in Fig. 2, it is darker than the male. The female laid eggs for the first time 10 days later (Table 1). Moreover, her post-mortem examination, 23 days later, showed that her bursa copulatrix was contracted, a clear sign that the female had been successfully mated (Naef, 1923).

\section{Male-male mating attempts}

A few mating attempts were also observed to occur among the males of Sepiola affinis clustered in the large tank.

The attempts may be described thus: a large male grabbed another male from below, while the latter was swimming, by placing arms III between the latter's head and mantle, just like the above described normal malefemale mating, as if the grabbed individual were a female. In most cases, the male in "female position" succeeded in shaking off the assaulting male. Only in a few instances, when the grabbed male was a weakened individual, forced copulation occurred and spermatophores were even transferred into his mantle cavity.

\section{Discussion}

This paper describes for the first time the mating behaviour in Sepiola intermedia and gives additional information on mating in Sepiola affinis and Sepietta obscura. Our observations largely coincide with recent observations on other Sepiolinae, both in the same genus Sepiola (Jones \& Richardson, 2010; Rodrigues et al., 2009) and in the genera Euprymna (Nabhitabhata et al., 2005; Squires et al., 2013) and Eumandya (Drerup et al., 2020).

Hereafter, we review details of all available observations on sepioline mating and discuss them (Table 2).

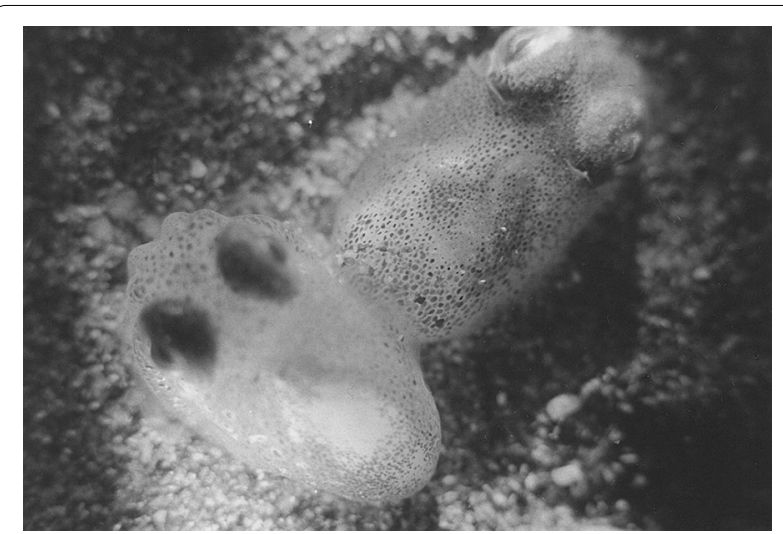

Fig. 2 Pair of Sepietta obscura resting after mating (female to the right) (photo @ Adrianne Deickert)
The first account on mating behaviour in Sepiolinae is found in Racovitza (1894). This paper describes mating in captive "Sepiola rondeletii" (in addition to Rossia macrosoma and Octopus vulgaris) collected off Roscoff (south-western entrance of the French-English Channel). According to these observations, the male brusquely grabbed the female and "turned her ventral face upward" before inserting his first pair of arms into her mantle cavity; his second arms were extended along her body (i.e., the mantle); the arms of the third pair around her neck; and the fourth ones within her arms. Mating lasted 8 min, during which time the male struggled to keep the female in position and the latter struggled desperately to get free, because (seemingly) it could not breath (Racovitza, 1894). This description corresponds very well to subsequent ones. The only inconsistency is that the observed species could not be $S$. rondeletii, because it is absent from that part of the Atlantic Ocean (cf. Bello, 2019); the best guess is that it was S. atlantica, a species that is comparatively common there in shallow waters.

Later, Levy (1912) gave a description of mating in $S$. atlantica both in words and in a drawing, the first visual representation of a sepioline mating (Fig. 3). Indeed, both word and drawing descriptions display some flaws with respect to other Authors.' The respective male and female positions correspond to other reports, but the account of the male tentacles embracing the female neck, while his third arms are kept bent inwards in the position of his own mouth appears quite questionable. As for Levy's (1912) figure (Fig. 3), once again the general male-female position is correct but not that of the male third and fourth arms, which reportedly do not hold the female.

Jaeckel (1958) wrote about mating in Sepiolidae without referring to a definite species. In addition, it is not clear whether the author actually observed mating in any species or simply referred to previous accounts; in fact, his description of the mating action is quite muddled. Nevertheless, he made important statements about the morphology of male's arms and suckers in relation to mating. That is, he pointed out the enlargement of middle arm suckers in latero-dorsal and ventral arms (this is a character typical of some species of Sepiola, cf. Naef, 1923), whose ensemble makes an "Apparatus fixator" (Jaeckel, 1958, p. 666) to hold the female during copulation. In particular, the male's ventral arms would thwart the female's arms so that the latter cannot use the funnel and flee quickly (during normal respiration, the water is drawn into the mantle cavity, flows over the gills and is ejected from the funnel; coleoid cephalopods may perform rapid locomotion by means of jet propulsion through the funnel; cf. Hanlon \& Messenger, 2018). Finally, Jaeckel (loc. cit.) stated that mating lasts 8-10 min. 
Table 2 Summary of observations on mating in Sepiolinae

\begin{tabular}{|c|c|c|c|c|c|}
\hline Genus & Species & References & Environment & Figurative documentation & Notes \\
\hline \multirow[t]{12}{*}{ Sepiola } & atlantica $^{\mathrm{a}}$ & Racovitza (1894) & A & - & Reported as Sepiola rondeletii \\
\hline & atlantica $^{b}$ & Levy (1912) & A & D & \\
\hline & atlantica $^{\mathrm{a}}$ & Rodrigues et. al. (2009) & A & $P$ & \\
\hline & atlantica $^{\mathrm{a}}$ & Jones and Richardson (2010) & A & - & \\
\hline & atlanticab $^{b}$ & Goud et. al. (2019) & $\mathrm{F}$ & $\mathrm{P}$ & \\
\hline & rondeletiic & Mangold-Wirz (1963) & & $\begin{array}{l}\text { D (general drawing for } \\
\text { Sepiolinae and Rossiinae) }\end{array}$ & $\begin{array}{l}\text { Seemingly not actually observed (description } \\
\text { after Racovitza, 1894) }\end{array}$ \\
\hline & affinis $^{b}$ & Mangold-Wirz (1963) & A & & \\
\hline & affinis $^{\mathrm{a}}$ & Mauris (1988) & A & $\mathrm{D}$ & \\
\hline & affinis $^{\mathrm{a}}$ & Present results & A & $\mathrm{D}$ & General drawing for all observed species \\
\hline & intermedia $^{\mathrm{a}}$ & Present results & A & $\mathrm{D}$ & General drawing for all observed species \\
\hline & sp..$^{c}$ & Jaeckel (1958) & & - & $\begin{array}{l}\text { Not clear whether mating was actually } \\
\text { observed }\end{array}$ \\
\hline & sp. $^{\text {b }}$ & Boletzky (1983) & A & - & Reported as Sepiola robusta \\
\hline \multirow[t]{2}{*}{ Sepietta } & obscura ${ }^{a}$ & Present results & A & $\mathrm{D}$ & General drawing for all observed species \\
\hline & oweniana ${ }^{c}$ & Bergström and Summers (1983) & & - & $\begin{array}{l}\text { Seemingly not actually observed (descrip- } \\
\text { tion after Racovitza, } 1894 \text { and Mangold-Wirz, } \\
\text { 1963) }\end{array}$ \\
\hline Eumandya & $p^{a r v a} a^{a}$ & Drerup et al. (2020) & A & $\mathrm{P}$ & \\
\hline \multirow[t]{5}{*}{ Euprymna } & scolopes $^{b}$ & Moynihan (1983) & A & - & \\
\hline & scolopes $^{b}$ & Singley (1983) & A & - & \\
\hline & scolopes $^{\mathrm{a}}$ & Hanlon et. al. (1997) & A & P & \\
\hline & hyllebergi $^{\mathrm{a}}$ & Nabhitabhata et. al. (2005) & A & $D$ and $P$ & \\
\hline & tasmanica $^{\mathrm{a}}$ & Squires et. al. (2013) & $A$ and $F$ & $\mathrm{P}$ & \\
\hline
\end{tabular}

Species: a detailed observations; ${ }^{b}$ partial observations; ${ }^{c}$ questionable. Environment: $A=$ aquarium; $F=$ field. Figurative documentation: $D=\operatorname{drawings;} P=$ photo

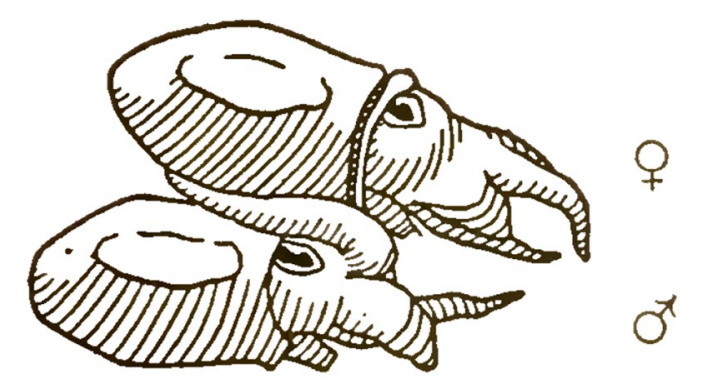

Fig. 3 Mating in Sepiola atlantica (after Levy, 1912)

Mangold-Wirz (1963, p. 129), after reporting Racovitza's (1894) description of mating, wrote "We have observed several times mating in Sepiola affinis in the aquarium. It progresses exactly as Racovitza described it in Sepiola atlantica". Further on, the same work gives an overall description of mating in Sepiolidae, where it is stated that it is short and the most violent among cephalopods, and that the female tries to get rid of the male.
The accompanying figure shows a male-to-female-neck mating position, which indeed does not correspond to subsequent descriptions and photographic evidences for Sepiolinae (Fig. 4). Anyway, in that position too, the male copulatory arm is aligned with the female bursa copulatrix.

Some subsequent reports are quite scanty. Boletzky (1983) compares his observations on Sepiola "robusta" [indeed, Sepiola sp. (Boletzky pers. comm.)] to Racovitza's (1894); notably, Boletzky (loc. cit.) reported that mating occurred always at night or in tanks kept in the dark. Bergström and Summers (1983) seemingly did not observe any mating in Sepietta oweniana but just likened it to Mangold-Wirz' (1963). Scanty as well are the reports by Moynihan (1983) and Singley (1983) on Euprymna scolopes mating.

Mauris (1988), in her thesis, provided detailed observations on some mating events in captive Sepiola affinis, all of them occurring at night. She wrote that the male grabs the female's neck by his third arms, which are short and thicker than the other arms; the male's third arms are also thicker than the female's third arms; both his first arms are inserted into the female mantle cavity; his second arms, which show to be very flexible, are lengthened 


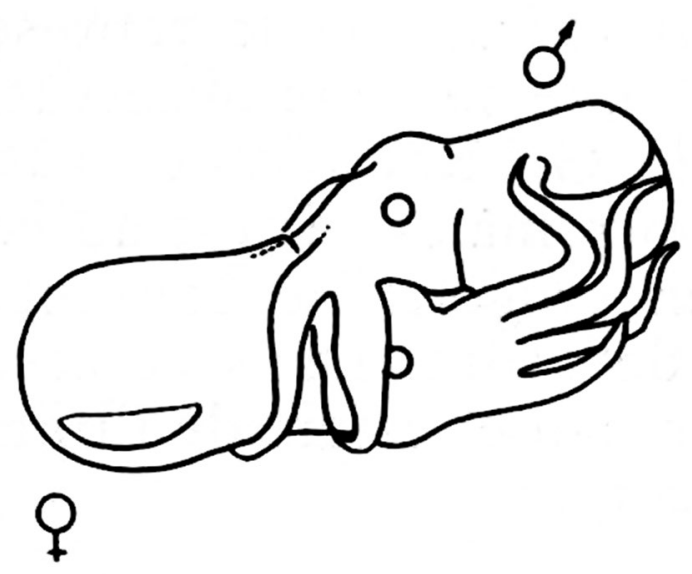

Fig. 4 Mating in the species of the genera Rossia, Sepiola and Sepietta (after Mangold-Wirz, 1963)

and placed on the ventral side of the female's mantle; his fourth arms are placed under the female's head. The female's mantle is at an angle of about $45^{\circ}$ with respect to the male plane and in this position the pair at first swims around and after a while, keeping on mating, go to rest on the bottom; here the female leans her arms on the ground. Mauris (1988) also discussed the behaviour of a male and a female of the same species placed together in a tank, where the female went to the bottom in a corner and kept still with her chromatophores expanded. Meanwhile, the male restlessly swam around her, keeping at about 5-6 $\mathrm{cm}$ distance, alternating swimming with staying still on the bottom of the tank with his arms spread out; this author herself was not able to judge, by just one observation, whether this behaviour might be deemed a courtship.

Detailed descriptions of mating are given by Hanlon et al. (1997) for Euprymna scolopes, Nabhitabhata et al. (2005) for Euprymna hyllebergi, Rodrigues et al. (2009) and Jones and Richardson (2010) for Sepiola atlantica, Squires et al. (2013) for Euprymna tasmanica, Drerup et al. (2020) for Eumandya parva. A concise description of copulation in Sepiola atlantica is given by Goud et al. (2019); this paper also includes a photograph of a mating pair taken in the wild. To these observations those of the present paper on Sepiola affinis, Sepiola intermedia and Sepietta obscura are to be added. Additional visual records of mating in the wild are given by the two photographs in Figs. 5 and 6, and by Miller (2019). In the latter document, the last two photographs show a mating pair of E. parva, where one can note the bulging of the female's ventral mantle due to the insertion of the male's first arms and a bunch of spermatophores during their transfer to the female.

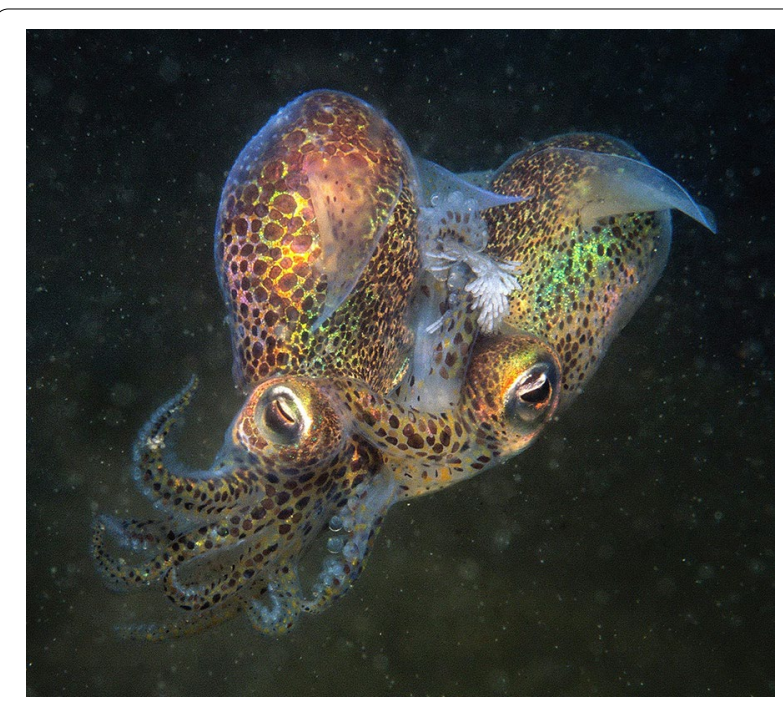

Fig. 5 Mating in Sepiola cf. atlantica in the field (female to the left). A bunch of white spermatophores can be seen held by the male's arms I and II. Oosterschelde (Netherlands), 3 m depth (photo @ Rokus Groeneveld, Netherlands)

All papers cited in the latter paragraph include pictorial representations showing that in Sepiolinae mating occurs in the parallel position. The laboratory observations match those recorded in the wild with respect to the mating position and are, thus, further corroborated. Only Mangold-Wirz' (1963) illustration (Fig. 4) does not match all these reports indicating the mating position; it is not possible to establish whether the position reported

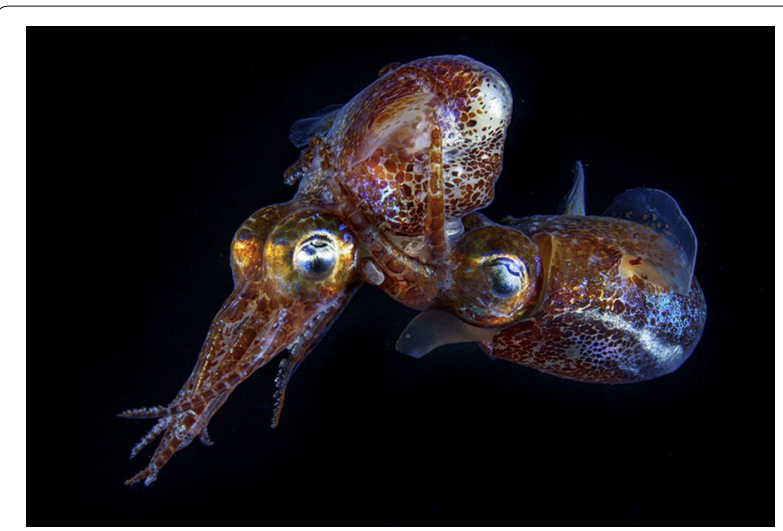

Fig. 6 Mating between Eumandya cf. parva (Gustavo Sanchez det.) in the field (female to the left). Male's arms I are inserted in the female's mantle cavity, as shown by the mantle bulging; arms II embrace the female's mantle and extend dorsally above the female's fins; arms III embrace the female's neck and join with each other slightly above the female's head; the proximal part of arms IV are attached to the female's head, the distal part is free. Okinawa (Japan), off Cape Kyan, time: 10 pm (photo @ Kenji Imai, Japan) 
in that paper, i.e., male-to-female-neck, was actually observed or just misinterpreted.

In the parallel mating position, the male hectocotylus is aligned with the female bursa copulatrix, both organs being on the left side of both sexes (Bello, 2020). Moreover, during copulation, the oral side of the hectocotylus, which carries and implants the spermatophores, faces the surface of the bursa copulatrix (this is particularly evident when taking into account the anatomy of sepiolines with the open-type bursa; cf. Bello, 2020). Therefore, the position of the hectocotylus (left dorsal arm) in the male and that of the bursa copulatrix (in the left ventral mantle cavity) in the female match perfectly with the parallel mating position, so that it is evident that the morphology of the sexual organs and the mating behaviour coevolved. In the parallel position the mates are not exactly parallel to each other, since the female mantle is somewhat tilted backwards. Possibly, mantle backward tilting facilitates the insertion of the hectocotylus inside the female mantle cavity.

As for the progress of mating, Nabhitabhata et al. (2005) subdivided the mating action into five stages (agreed with by Rodrigues et al., 2009): (a) female hovers by, male attention; (b) male approaches female from below; (c) male grasps female by mantle; (d) male's grasp moves to female's neck; (e) male pulls female down to substrate. Two more stages may be added to the five above: (f) copulation and (g) mating dissolution.

Stage (a)-All cited recent authors agree that mating events were not accompanied by any evident courtship behaviour. In particular, Rodrigues et. al. (2009) state that, indeed, it is the female that initiates mating by hovering over the male; a stance that is reported by all authors. In our opinion, the female while hovering might possibly send light cues to the male indicating her presence and availability to mate; in fact, according to the present results, the male fixed his eyes on the female for a few seconds before approaching her. All accurately observed species (with the exception of Sepietta obscura) belong to genera provided with visceral light organs, i.e., Sepiola, Eumandya and Euprymna. Most Sepiolinae, except the genera Inioteuthis and Sepietta, bear light organs embedded in the ink sac (Bello, 2020), hence visible from below when hovering above the ground. Close examination of mating in those genera lacking a light organ may contribute to clear up this matter, since the only observed mating event in Sepietta obscura (Deickert, 2009; present results) occurred in natural daylight (this remark does not imply that S. obscura mates only in daylight). Whether light cues are sent by hovering females or not, the female pre-mating behaviour might, however, represent courtship by the female. Incidentally, such hypothetical female's courtship (hovering over the male), possibly evolved in ancestral sepiolines provided with light organs (a plesiomorphic feature), might persist also in the species that lost the light organs as a remnant of their evolutionary history; that is, they might still exhibit hovering behaviour to attract the male, even if they are not emitting light.

Stage (b) - Universally agreed with.

Stages (c) and (d)-Also generally agreed with. All literature accounts point out that this phase is rather violent and that the female tries to escape the male grip. Conversely, the male uses the power of his arm suckers to hold the female; at least arm pairs II and III are involved in holding the female. As for the male's second pair of arms placed on the ventral side of female's mantle, they might also help in keeping the female's mantle open and facilitate both the insertion of the male's first arms and the transit of spermatophores (see male's II right arm pulling female's mantle skin in Rodrigues et al., 2009, Fig. 1b). All mating descriptions, except Levy (1912), mention that the male arms of the III pair exert a vigorous grip on the female neck, which explains why these arms are thicker in the adult male of several species, including Sepietta oweniana, Sepiola bursadhaesa (cf. Bello, 2013) and Boletzkyola knudseni (cf. Bello, 2020). Moreover, additional sexual dimorphisms, including enlarged latero-dorsal arm suckers in the males of several species (Naef, 1923) and the male arms being comparatively longer than those of females (e.g., S. bursadhaesa; cf. Bello, 2013), might also be related to the male holding of the female during mating.

Stage (e)-Male carrying female to the ground seemingly did not occur in all observed cases (e.g., Drerup et al., 2020; present results). Therefore, this stage might be omitted from a general series of behaviours.

Stage (f)-Copulation proper occurs with the insertion of the hectocotylus inside the female mantle for the transfer of spermatophores and their implantation into the bursa copulatrix. The hectocotylus insertion ensues the achievement of male-female positioning, i.e., stage (d). According to the various accounts, it is not clear whether just the hectocotylus or both male dorsal arms are introduced into the female mantle cavity. We believe that the latter case is the right one. Therefore, each arm enters the corresponding side of the female cavity. In any case, the male left dorsal arm or hectocotylus enters the female left mantle cavity, where the bursa copulatrix is located, as already reported above. Steenstrup (1857, p. 92) described "a remarkable dilatation of the skin developed at the base of the inner surface of the arm (i.e., the hectocotylus), strongly provided with muscles, and thus rendered capable of dilating itself towards the sides and folding itself together, so that it appears able to act as a prehensile apparatus or forceps", which apparatus, later 
named the 'copulatory apparatus' by Naef (1916), is formed by a group of highly modified sucker stalks in the proximal third of the arm in all sepioline genera except Eumandya and Euprymna (cf. Bello, 2020). In the latter two genera, the copulatory apparatus is quite rudimentary, but the distalmost portion of the hectocotylus is highly modified into palisades (Bello, 2020; Norman \& $\mathrm{Lu}, 1997)$. Therefore, we can generally deem that at least in the genera with a well-developed copulatory apparatus (namely, Adinaefiola, Boletzkyola, Inioteuthis, Lusepiola, Rondeletiola, Sepietta and Sepiola) the spermatophores are carried to the female by the copulatory apparatus, as stated by Steenstrup (1857) (it is not clear whether this Author actually observed the copulatory apparatus action or just envisaged it). The other piece of information given by Steenstrup (1857), that is the dilatation of the copulatory apparatus during mating, has not been reported subsequently by any author. Contrary to this, Squires et. al. (2013, p. 266) showed that in Euprymna tasmanica "at the conclusion of mating [...] the male's hectocotylus was enlarged, in some cases to nearly twice its original width"; in the accompanying photograph (Squires et al., 2013, Fig. 1D), it is clear that it is the palisaded portion of the hectocotylus that has actually undergone enlargement. In this respect, Bello (2020) suggested a possible correspondence between hectocotyli with large sucker stalks in their distal portion (Eumandya, Euprymna, Lusepiola) and the closed-type bursa copulatrix. Moreover, Squires et. al. (2013, Fig. 1B) as well as Drerup et. al. (2020, Fig. 7C) display photographs, where a bundle of spermatophores is out of the male body ready to be carried to the female mantle cavity. In particular, the figure shows spermatophores coming out the male funnel of Euprymna tasmanica and the latter figure shows spermatophores held by the dorsal pairs of arms of Eumandya parva, before their insertion into the female mantle cavity. An additional photographic document (Fig. 5) shows a bundle of spermatophores manipulated by the male left arms I and II during mating in Sepiola cf. atlantica, seemingly ready to be introduced into the female mantle cavity. It is not clear how spermatophores are handled by the male arms from their exit out of the funnel to the taking by the hectocotylus. Finally, the duration of the copulation stage is rather variable from a few minutes (Nabhitabhata et al., 2005; Racovitza, 1894; present results) to $3 \mathrm{~h}$ (Squires et al., 2013), most frequently between 30 and $80 \mathrm{~min}$ (Drerup et al., 2020; Hanlon et al., 1997; Jones \& Richardson, 2010; Rodrigues et al., 2009; Squires et al., 2013).

Stage (g)-Dislodgement of the hectocotylus and conclusion of mating. This aspect of mating has been barely addressed by the various authors. Only MangoldWirz (1963) mentions that the mates move away from each other very sharply, because the female breathing was curbed during copulation. It appears that the male extracts its hectocotylus from the female mantle cavity and at the same time loses the suckers grip on the female body and set her free, so that the two mates soon move apart from each other. An exception is represented by the behaviour of Sepietta obscura, because the two mates came very close together shortly after mating (present results). As mentioned above, Squires et. al. (2013) commented on the hectocotylus enlargement.

In summary, the following stages may be accounted for: (A) female hovers by, male attention; (B) male approaches female from below; (C) male grasps female, positions itself and they mate in the parallel position (which includes insertion of first pair of arms into the female mantle cavity); (D) copulation and transfer of spermatophores from male to female; (E) mating dissolution. Capital letters were used to distinguish the present stages from Nabhitabhata et al's (2005).

During mating, changes in the colour pattern of both mates occur. Descriptions of the various observations vary to some extent. In general, during copulation the male becomes darker than before because of chromatophores expansion, whereas the female remains paler (Nabhitabhata et al., 2005; Rodrigues et al., 2009; present results).

Another trait common to all observed species is the male aggressiveness and the female resistance to being held by the male. In our opinion this behaviour is not necessarily related to the female breathing constraint, because the female displays her freeing efforts from the very onset of being grabbed by the male. Moreover, this female behaviour is at odds with the supposition that the female solicits mating; see Stage (a) above.

Mating in Sepiolinae appears to occur preferentially during the hours of darkness, which is a further support to the hypothesis that the female visceral luminous glands might play a role in triggering the male response in species with luminous organs.

Finally, a most variable parameter is the copulation length, from short, i.e., few minutes (Racovitza, 1894, in Sepiola atlantica; Mangold-Wirz, 1963, in Sepiola affinis; Nabhitabhata et al., 2005, in Euprymna hyllebergi; present results in Sepietta obscura) to long, i.e., from one half to 3 h (Hanlon et al., 1997, in Euprymna scolopes; Squires et al., 2013, in Euprymna tasmanica; Rodrigues et al., 2009, and Jones \& Richardson, 2010, in Sepiola atlantica; Drerup et al., 2020, in Eumandya parva; present results in Sepiola affinis and Sepiola intermedia). It is noticeable that both short and long copulation times have been recorded in the same species, i.e., Sepiola atlantica and Sepiola affinis, or in the same genus, i.e., Euprymna. A conceivable question is: is copulation successful when it is short? Among the short-mating reports 
both Nabhitabhata et al. (2005) and the present results about Sepietta obscura mention that mating was followed by egg laying. Nevertheless, at least in our case involving wild-caught Sepietta obscura, it might be alternatively supposed that copulation did not progress, because the female had been already mated, and therefore, her bursa copulatrix was contracted (regarding post-copulation contraction of the bursa see Naef, 1923). Indeed, the hypothesis that multiple mating might not occur in Sepiolinae is contradicted by its detection in Euprymna tasmanica (Squires et al., 2012).

Our observations on male-male mating in Sepiola affinis conforms to reports of spermatangia implanted on the body of wild-caught male sepiolid squids (e.g. Jaeckel, 1958; Racovitza, 1894; G.B. personal observations), which is an evidence that this anomalous behaviour occurs in the wild too. Moreover, the fact that the assaulting male attacks his potential-but-wrong mate, while the latter is swimming above the former is a further clue that it is the sight of an individual hovering above that triggers the compulsion to mate in males.

As early as half a century ago, Mangold-Wirz (1963) wrote that mating occurs in the same way in all species of Sepiolidae. The recent literature and present results show that in Sepiolinae mating indeed follows a common pattern in all its features, apart few minor details. Further observations, especially in deep water species would be important to corroborate the above statement. This occurs even in genera substantially differing in copulatory organ morphology, i.e., a hectocotylus with either a well-developed copulatory apparatus (Sepiola and Sepietta) or quite enlarged palisaded distal portion (Eumandya and Euprymna); bursa copulatrix either of the open type (Sepiola and Sepietta) or the closed type (Eumandya and Euprymna). Undoubtedly, the shared mating physiology and behaviour in this taxon depends on a common evolutionary path parallel to the common morphological evolutionary trajectory that led to the hectocotylization of the left dorsal arm in males and the development of the bursa copulatrix in females; the same trajectory led also to the strengthening of third arms and the enlargement of lateral arm suckers in males of some species (Bello, 2020; Mangold-Wirz, 1963; Naef, 1923).

\section{Conclusions}

It is quite evident that mating follows a pattern common to all members of Sepiolinae examined to date, which is a clear indication that it is a genetically programmed behaviour shared by all members of this taxon. Furthermore, it is also evident that this common mating pattern evolved in harmony with the sepioline peculiar copulatory organs (hectocotylus and bursa copulatrix) (Bello, 2020) as well as other morphological features (third arms stouter and lateral arm suckers larger in males). The coevolution of morphological and behavioural traits is a further indication of the close phylogenetic affinities among all sepioline genera and species. In turn, a behavioural trait, mating, is a valid tool to contribute when assessing phylogenetic affinities. In fact, the Sepiolinae shared mating behaviour may be deemed a synapomorphic character.

Finally, the present review of the mating behaviour constitutes an essential piece in the ethogram of Sepiolinae as a clade (i.e., an evolutionary unit) of Sepiolida. The ethogram was in fact defined as "an inventory of the behavior of a species" (Drickamer et al., 1996, p. 17); in the present case this concept is extended to a whole taxon, the subfamily Sepiolinae. Such an extension is feasible because of the close matching among the specific mating behaviours and is also supported by the withinSepiolinae genetic affinities.

\section{Acknowledgements}

The present observations on mating in Sepiola affinis, Sepiola intermedia and Sepietta obscura were part of research on reproduction in several sepioline species in accomplishment of the Ph.D. thesis of A. D. under the guidance of Dr. Sigurd Boletzky. We are most grateful to him for his friendly support to both of us during many years. We also acknowledge the contribution by the photographers Mr. Rokus Groeneveld (Netherlands) and Mr. Kanji Imai (Japan), who very kindly offered permission to reproduce their photographs; Dr. Gustavo Sanchez in the identification of a photographed pair of sepiolines; Dr. Amanda Reid, who suggested an internet article; Mr. Shawn Miller for providing details on the sepioline mating pair photographed in his article; and two anonymous reviewers for their helpful suggestions.

\section{Authors' contributions}

GB analysed the data, reviewed the literature and was a major contributor to writing the manuscript. AD carried out the laboratory observations, analysed the data, prepared drawings, reviewed the literature and contributed to writing the manuscript. Both authors read and approved the final manuscript.

\section{Funding}

The experimental part of the present work was carried out during the AD's research periods at the Laboratoire Arago in Banyuls-sur-Mer (France) for the accomplishment of her thesis funded by the Graduiertenförderung des Landes Berlin and the Deutscher Akademischer Austauschdienst. The observation analysis and manuscript preparation were performed with personal funds of both authors.

\section{Availability of data and materials}

All data used in the present paper are reported in Table 1.

\section{Competing interests}

The authors declare that they have no competing interests.

Author details

${ }^{1}$ Mola di Bari, Italy. ${ }^{2}$ Schriesheim, Germany.

Received: 11 May 2021 Accepted: 2 July 2021

Published online: 05 October 2021

\section{References}

Bello, G. (2013). Description of a new sepioline species, Sepiola bursadhaesa n. sp. (Cephalopoda: Sepiolidae), from the Catalan Sea, with remarks and identification key for the Sepiola atlantica group. Scientia Marina, 77, 489-499. 
Bello, G. (2019). The Mediterranean Sepiolidae (Mollusca Cephalopoda) diversity. Biodiversity Journal, 10, 389-404.

Bello, G. (2020). Evolution of the hectocotylus in Sepiolinae (Cephalopoda: Sepiolidae) and description of four new genera. European Journal of Taxonomy, 655, 1-53.

Bergström, B., \& Summers, W. C. (1983). Sepietta oweniana. In P. R. Boyle (Ed.), Cephalopod life cycles. Species accounts (Vol. 1, pp. 75-91). Academic Press.

Bhaud, M., Jaques, G., \& Razouls, C. (1967). Données météorologiques et hydrologiques de la région de Banyuls-sur-Mer. Année 1965-1966 (point côtier). Vie et Millieu, 18, 137-151.

Boletzky, S. v. (1983). Sepiola robusta. In P. R. Boyle (Ed.), Cephalopod life cycles. Species accounts (Vol. 1, pp. 53-67). Academic Press.

Deickert, A. (2009). Reproductive mode in the genus Sepietta (Cephalopoda: Sepiolidae). Bollettino Malacologico, 45(suppl.), 87-94.

Drerup, C., Sykes, A. V., \& Cooke, G. M. (2020). Behavioural aspects of the spotty bobtail squid Euprymna parva (Cephalopoda: Sepiolidae). Journal of Experimental Marine Biology and Ecology, 530-531, 151442.

Drickamer, L. C., Vessey, S. H., \& Meikle, D. (1996). Animal behavior: Mechanisms, ecology, 915 and evolution (4th ed.). W. C. Brown.

Goud, J., de Heij, A., \& Hiemstra, A.-F. (2019). Cephalopods in the North Sea. Vita Malacologica, 18, 34-57.

Hanlon, R. T., Claes, M. F., Ashcraft, S. E., \& Dunlap, P. V. (1997). Laboratory culture of the sepiolid squid Euprymna scolopes: A model system for bacteriaanimal symbiosis. The Biological Bulletin, 192, 364-374.

Hanlon, R. T., \& Messenger, J. B. (2018). Cephalopod Behaviour (2nd ed.). Cambridge University Press.

Jaeckel, S. G. A. (1958). Cephalopoden. In G. Grimpe \& E. Wagner (Eds.), Die Tierwelt der Nord- und Ostsee (Vol. 37, pp. 479-723). Akad. Verlagsges.

Jones, N. J. E., \& Richardson, C. A. (2010). Laboratory culture, growth, and the life cycle of the little cuttlefish Sepiola atlantica (Cephalopoda: Sepiolidae). Journal of Shellfish Research, 29, 241-246.

Levy, F. (1912). Observations sur les Sépioles des côtes de France. Archives de Zoologie Expérimentale et Générale, 5e sér., 9, Notes et Revue (3): LIV-LIX.

Mangold-Wirz, K. (1963). Biologie des Céphalopodes benthiques et nectoniques de la Mer Catalane. Vie et Milieu, 13, 1-285.

Mauris, M.-E., (1988). Comportement prédateur de la sépiole (Sepiola affinis): Approches expérimentales en éco-éthologie. Thèse de Doctorat de la I'Université Paris 6, 108.
Miller, S. (2019). Master of evasion-The Bobtail Squid of Okinawa. Okinawa Nature Photography. https://okinawanaturephotography.com/masters-ofevasion-the-bobtail-squid-of-okinawa/

Moynihan, M. (1983). Notes on the behavior of Euprymna scolopes (Cephalopoda: Sepiolidae). Behaviour, 85, 25-41.

Nabhitabhata, J., Nilaphat, P., Promboon, P., \& Jaroongpattananon, C. (2005). Life cycle of cultured bobtail squid, Euprymna hyllebergi Nateewathana, 1997. Phuket Marine Biology Center Research Bulletin, 66, 351-365.

Naef, A. (1916). Ueber Neue Sepioliden aus dem Golf von Neapel. Pubblicazioni della Stazione Zoologica di Napoli, 1, 1-10.

Naef, A. (1923). Die Cephalopoden. Fauna und Flora des Golfes von Neapel, 35(1), $1-863$.

Norman, M. D., \& Lu, C. C. (1997). Redescription of the southern dumpling squid Euprymna tasmanica and a revision of the genus Euprymna (Cephalopoda: Sepiolidae). Journal of the Marine Biological Association of the United Kingdom, 77, 1109-1137.

Racovitza, E. G. (1894). Sur l'accouplement de quelques Céphalopodes, Sepiola rondeleti (Leach), Rossia macrosoma (D. Ch.) et Octopus vulgaris (Lam.). Comptes Rendus Hebdomadaires Des Séances De L'académie Des Sciences, $118,722-724$

Rodrigues, M., Garci, M. E., Guerra, Á., \&Troncoso, J. S. (2009). Mating behavior of the Atlantic bobtail squid Sepiola atlantica (Cephalopoda: Sepiolidae). Vie et Milieu, 59, 271-275.

Singley, C. (1983). Euprymna scolopes. In P. R. Boyle (Ed.), Cephalopod life cycles. Species accounts (Vol. 1, pp. 69-74). Academic Press.

Squires, Z. E., Norman, M. D., \& Stuart-Fox, D. (2013). Mating behaviour and general spawning patterns of the southern dumpling squid Euprymna tasmanica (Sepiolidae): A laboratory study. Journal of Molluscan Studies, $79,263-269$.

Squires, Z. E., Wong, B. M., Norman, M. D., \& Stuart-Fox, D. (2012). Multiple fitness benefits of polyandry in a cephalopod. PLOS ONE, 7, e37074.

Steenstrup, J. (1857). Hectocotylus-formation in Argonauta and Tremoctopus explained by observations on similar formations in the Cephalopoda in general. The Annals and Magazine of Natural History, 20, 81-114.

\section{Publisher's Note}

Springer Nature remains neutral with regard to jurisdictional claims in published maps and institutional affiliations.

\section{Submit your manuscript to a SpringerOpen ${ }^{\circ}$ journal and benefit from:}

- Convenient online submission

- Rigorous peer review

- Open access: articles freely available online

- High visibility within the field

- Retaining the copyright to your article

Submit your next manuscript at $\boldsymbol{\Delta}$ springeropen.com 